\title{
Morfologia das diferenças: um estudo sobre o desempenho urbano da Quadra 806 Sul, Palmas, Tocantins, Brasil
}

Morphology of the differences: a study about the urban performance of the Quadra 806 Sul, Palmas, Tocantins, Brazil

\section{Morphologie des différences: une étude sur la performance urbaine du Quadra 806 Sul, Palmas, Tocantins, Brésil}

\section{Morfología de las diferencias: un estudio sobre el desempeño urbano del Quadra 806} Sul, Palmas, Tocantins, Brasil

\author{
Nicole de Castro Pereira* \\ (nicole@ifsp.edu.br)
}

Recebido em 10/02/2016; revisado e aprovado em 09/04/2016; aceito em 15/04/ 2016 DOI: http:/ / dx.doi.org/10.20435/1984-042X-2016-v.17-n.3(06)

\begin{abstract}
Resumo: Este estudo compara duas regiões da Quadra 806 Sul em Palmas, Brasil. Aborda-se o panorama geral da organização espacial e ocupação territorial da quadra e verificam-se aspectos gerais de urbanidade. O desempenho urbanístico é estimado dentro do conceito da sintaxe espacial. Os resultados evidenciam como a arquitetura afeta a conduta dos moradores e revelam que as condições climáticas também podem ter papel fundamental no desempenho urbanístico de uma região.
\end{abstract}

Palavras-chave: desempenho urbano; urbanidade; sintaxe espacial.

\begin{abstract}
This study compares two regions of the Block 806 South, Palmas, Brazil. It approaches spatial organization and territorial occupation of the block and verifies general urbanity aspects. The urban performance has been estimated based on the concepts of spatial syntax. Results show evidences on how Architecture affects the behaviour of the resident and reveal that climate might have a fundamental role in the urban performance of an area.
\end{abstract}

Key words: urban performance; urbanity; spatial syntax.

Résumé: Cette étude compare deux régions du Bloc du Sud 806, Palmas, Brésil. Il aborde une disposition spatiale et l'occupation territoriale du bloc en vérifiant les aspects générale de l'urbanité. La performance urbaine a été évaluée dans des concepts de la syntaxe spatiale. Les résultats montrent la façon dont l'architecture affecte le comportement des résidents, et révèlent que le climat (les conditions climatiques) peuvent avoir un rôle fondamental sur la performance d'une zone urbaine.

Mots-clés: performance urbaine; urbanité; syntaxe spatiale.

Resumen: Este estudio compara dos áreas del Bloque 806 Sur, Palmas, Brasil. Aborda el panorama general de la organización espacial y la ocupación territorial del bloque y lo revisa cuestiones generales de la urbanidad. Lo desempeño urbano se estima dentro del concepto de la sintaxis espacial. Los resultados muestran cómo la arquitectura afecta el comportamiento de los residentes y demostran que las condiciones climáticas también pueden tener un papel fundamental en lo desempeño de una zona urbana.

Palabras clave: desempeño urbano; urbanidade; sintaxis espacial.

\section{INTRODUÇÃO}

A criação e a formação dos espaços, individuais e coletivos, sempre aconteceram. Morfologia, no seu sentido amplo, significa o estudo das formas. José Lamas
(1992) define que "é a disciplina que estuda o objeto - a forma urbana - nas suas características exteriores, físicas, e na sua evolução no tempo".

Ao se relacionar morfologia com a arquitetura da cidade e com processos de

\footnotetext{
* Curtin University, Bentley, Austrália.
} 
composição e decomposição espacial, há que se considerar e estabelecer relações próximas ao ambiente edificado, indivíduo e sociedade. A cidade, a quadra, a rua, a casa e o quintal. O indivíduo e a sociedade.

Segundo Pescarini (2003), a morfologia da cidade estrutura-se para afirmar relações ideológicas e culturais onde acontecem vivências e processos de troca. Constitui um universo dinâmico associado, desde o princípio, aos arranjos de processos sociais existentes rotineiramente. Admitindo essa concepção, determinada sociedade (e consequente indivíduo) inserida em um determinado espaço é objeto diretamente afetado pela arquitetura desse espaço. Holanda (2003) descreve que algumas afetações são simultaneamente mais evidentes e menos controversas e define 'aspectos de desempenho' do espaço arquitetônico como sendo as maneiras pelas quais a arquitetura - como espaço pronto - influencia o comportamento humano.

Sobre sintaxe espacial e desempenho urbanístico, Frederico de Holanda (2003, p. 5) esclarece:

[...] espaço arquitetônico nos afeta, independente da escala em que se apresente: edifício individual, bairro, cidade inteira, paisagem regional. Algumas afetações são mais evidentes e menos controversas. Não há muita discussão em torno de uma casa poder atingir-nos como mais quente/ fresca, mais apertada/espaçosa, mais cara/barata de construir, que nos encanta por sua originalidade ou nos parece banal. Essas e outras maneiras da arquitetura atingir-nos podem ser chamadas de aspectos de desempenho do espaço arquitetônico. Referem-se a como ele responde às nossas expectativas de conforto ambiental, funcionais, econômicas, estéticas, etc. Surge o primeiro divisor de águas: não nos interessam inten- ções declaradas ou camufladas (o inferno tem muitas) que pressupostamente originaram o edifício. Importa-nos os resultados no espaço pronto, como nos afetam.

Ele ressalta que a Teoria da sintaxe espacial foi sugerida por Bill Hillier e seus colaboradores da Bartlett School Graduate Studies, em Londres. De acordo com a teoria, a determinação da utilização de um espaço é concebida com um paralelo entre forma, espaço do meio urbano e comportamento humano. Visa-se, dessa maneira, estudar as relações entre a configuração de cidades e edifícios e a forma como as pessoas permanecem ou se movem, além das implicações sociais disto (HOLANDA, 2003).

Palmas foi projetada e implantada há menos de trinta anos e possui características morfológicas recorrentes em cidades brasileiras de criação recente. Embora sua configuração geral seja geométrica, cada quadra dentro do perímetro urbano possui propriedades singulares. Designada a ter sua implantação ao lado direito do rio Tocantins, foi desenhada sua área urbana, com 11.085 ha de terra e previsão de abrigar cerca de um milhão e duzentos mil habitantes.

O marco inicial da construção foi a Praça dos Girassóis, onde está localizado o centro administrativo estadual e o cruzamento entre as princiapais vias da cidade. Três vias no sentido norte-sul (TO 134, a Av. Teotônio Segurado e a Av. Parque) e uma no sentido leste-oeste (Av. Juscelino Kubitschek) estruturam o sistema viário da cidade. Entre elas, paralelamente, outras avenidas completam a malha urbana viária, dividindo a cidade em grandes quadras destinadas a diversas funções. A partir daí, seguem, no interior das quadras, as vias secundárias que completam a hierarquia do sistema viário, junto com as vias de pedestres, as ruas e as alamedas.

A partir dos eixos viários, foram delimitadas as seguintes áreas: residenciais; de comércio e serviço vicinal, de comércio 
e serviço local, de comércio e serviço regional e industrial; social, cultural e recreacional; verdes; de equipamentos; e administrativo-institucional.

Silva (2002) destaca que as áreas residenciais foram planejadas para serem bairros semiautônomos, com quadras de aproximadamente 42 hectares, dotados de tipologias residenciais diversas, edifícios de funções complementares, tais como creches, postos de saúde e policial, praças de esporte, recreação e comércio local. Conforme o Plano Diretor (PALMAS, 1994), os equipamentos são destinados tanto para o atendimento às demandas da sua população, como para funcionar como mecanismos de integração social.

As quadras foram concebidas por diferentes arquitetos e têm morfologias diferenciadas. Conforme Silva (2010), o caráter modernista subtrai-se por meio de vários elementos diferenciadores, entre eles o fato deas quadras funcionarem como vilas, tendo vários usos no seu interior. Entretanto, nesse mesmo trabalho, a autora afirma que "o Grupo Quatro organizou seu projeto urbanístico segundo as funções da Carta de Atenas; Palmas é o exemplo da aplicação de boa parte dos princípios funcionalistas da Carta de Atenas e dos CIAM" (SILVA, 2010). Nesse tópico, inúmeras são as opiniões divergentes acerca do processo de formação da cidade, desde a definição do sítio, a escolha da capital do estado do Tocantins provisória (sediada em Araguaína durante a construção de Palmas), a obra, os conceitos e intenções urbanísticos, políticos e sociais envolvidos no projeto.

A Quadra 806 Sul é uma das mais antigas de Palmas, embora a cidade não tenha completado ainda três décadas de existência. O Plano Inicial sugeria que a cidade deveria crescer ordenadamente e em faixas contínuas (SOUZA, 1992), diferentemente do que se constata hoje pelos numerosos vazios urbanos dentro do Plano e populosos núcleos satélites nas suas proximidades.
É uma área de uso predominantemente residencial, denominada na Lei Municipal de Uso e Ocupação do Solo (PALMAS, 1993) como Área Residencial Sudeste (ARSE) e inclui equipamentos que lhe são complementares - comércio, serviço, instituição de educação e área esportiva. Existem dois acessos, sendo um deles ao leste, e o outro, a oeste, e ambos com características visivelmente particulares.

Este trabalho visa identificar, analisar e comparar peculiaridades dos dois acessos à quadra, identificando sistemas de barreiras e permeabilidades ao movimento, e opacidades e transparências à visão que impliquem condições desejáveis à permanência e movimento de pedestres e veículos. Também a localização, quantidade e tipo das atividades realizadas que impliquem relações entre pessoas e grupos.

A fim de estimar o desempenho urbanístico da quadra, sua configuração urbana será analisada, dentro de elementos da Teoria da Sintaxe Espacial e da Teoria dos Aspectos Topoceptivos do desempenho da forma da cidade, através de dados indicativos dos relativos aos seguintes itens: 1) intensidade, sexo e idade média de pessoas nos espaços abertos de uso coletivo próximos a cada um dos acessos; 2) horários de concentração de pessoas; 3) atividades realizadas nos espaços públicos. O estudo foi realizado no ano de 2008, e a descrição dos espaços é baseada em conhecimentos empíricos adquiridos naquela época.

\section{A QUADRA À PRIMEIRA VISTA}

O senso comum dos moradores de Palmas destaca a Quadra 806 Sul dentro do cenário municipal. Por possuir aglomerações pontuais e temporais de pessoas em suas áreas públicas, em especial junto à sua praça, a utilização da quadra opõe-se ao que acontece na maioria das demais quadras da cidade, onde predomina a 
desertificação e o vandalismo dos espaços públicos. A Quadra 106 Sul, por exemplo, adota preceitos modernistas de se fazer - e zonear - a cidade e mostra, nos seus espaços destinados ao uso coletivo, aspectos contrários aos preceitos de urbanidade propostos por Holanda (2003), caracterizados por “a) minimizar espaços abertos em prol de ocupados; b) menores unidades de espaço aberto (ruas, praças); c) maior número de portas abrindo para lugares públicos (jamais paredes cegas); d) minimizar espaços segregados, guetizados (becos sem saída, condomínios fechados) e efeitos panópticos pelos quais tudo se vê e vigia." Sua praça é uma grande área aberta com espaços proporcionais aos destinados para os edifícios residenciais. Além disso, é cercada de muros e paredes cegas, rodeada de acessos de pedestres isolados, estreitos e sem iluminação e ainda, limitada por ruas sem saída. Resultado: configuração espacial provoca sistemas de encontros sociais fora dos espaços públicos.

Del Rio e Gallo (2000) opinam que a abordagem modernista de quebra da visão das cidades como contínuo promoveu, não só no Brasil, mas no mundo todo, o monofuncionalismo e o esvaziamento dos espaços urbanos. Segundo ele, isso gerou áreas propensas à marginalidade e inseguras, de reversão comprometida, como podem ser verificadas em Palmas.

No caso da 806 Sul, a quadra é marcada por somente dois acessos de veículos, um deles a oeste e o outro a leste. No alinhamento dos acessos, onde se forma o eixo que divide a quadra simetricamente, estão as áreas a serem analisadas. As ruas (ou alamedas, como são chamadas) têm seus lotes predominantemente ocupados. As construções são, em sua maioria, térreas e unifamiliares, com mínimas exceções. Um condomínio multifamiliar de quatro pavimentos implantado na entrada leste, por exemplo, alguns poucos pontos de comércio e sobrados.

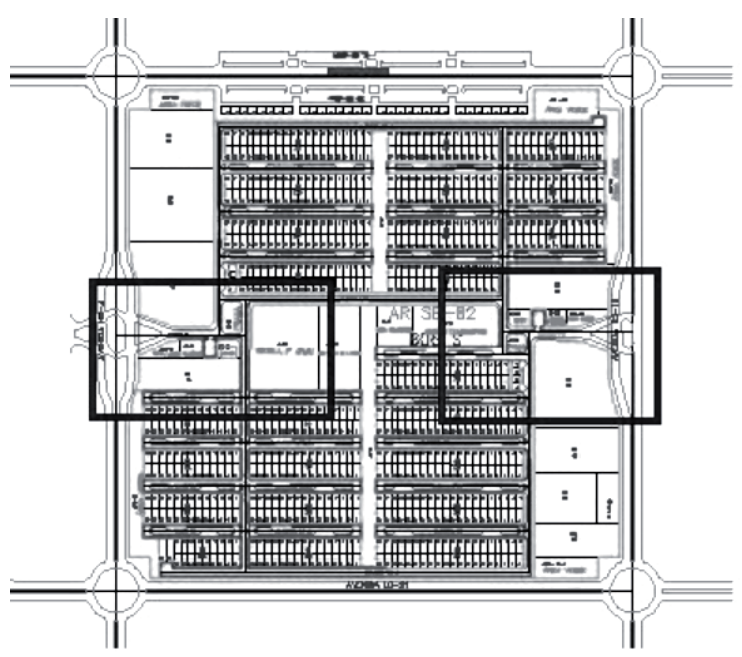

Figura 1 - Quadra 806 e delimitação das áreas de estudo

Com visada e acesso diretos para a praça, está a entrada oeste. A praça abriga uma pista para caminhada, um quiosque no qual funciona um comércio noturno (alimentação e bebidas), quadra de esportes e parque infantil, bem como um limitado estacionamento de veículos. Em esquinas opostas, estão uma mercearia e um edifício religioso e, posteriormente à praça, uma escola. Todas as edificações residenciais ao redor têm seus acessos principais voltados para esses espaços públicos.

No ano em que o estudo foi realizado, as calçadas ainda não estavam finalizadas, e a vegetação ainda era nova. Não havia árvores de sombra no local, em nenhum dos acessos.

Em uma breve caminhada pelas ruas fora do eixo de simetria, onde está disposta a maioria das edificações residenciais, percebe-se que, na vasta maioria delas, há pessoas sentadas nas calçadas, em cadeiras ou no chão, e crianças brincando nas ruas. Nesse caso, a edilícia moderna, onde se busca um espaço "mais aberto", de densidades baixas procedentes das cidades-jardim, outrora indispensável nas cidades novas, é minimizada, e se ganha em urbanidade. Assim, é clara a identidade da rua como continuação entre casa e espaço público, entre indivíduo e 
sociedade. Embora a ideia de rua como um espaço fechado e formalmente definido permaneça, quando não são paredes-cegas que se voltam para ela, a casa é elemento de composição do todo, e não entidade limítrofe.

Para análise de dados e posterior formulação de resultados, executou-se o mapeamento em dois horários, sendo o primeiro no período da tarde compreendido entre catorze e dezesseis horas e o segundo entre as dezenove e vinte e uma horas. O levantamento foi realizado para demonstrar a utilização padrão dos espaços da 806 Sul naquela fase de desenvolvimento da região.

No mapeamento, localizaram-se espacialmente, durante o horário determinado, pessoas (entre crianças, mulheres e homens) subclassificadas em 'em circulação', quando em trânsito, ou 'em atividade', quando fazendo uso de um ou mais equipamentos urbanos.

\section{3 À SEGUNDA VISTA: INTEGRAÇÃO DOS FLUXOS}

Com relação ao fluxo de veículos dentro da quadra, aplicou-se o método da axialidade, da teoria de sintaxe espacial. Sob a teoria, quando se processa um mapa axial, o resultado medirá a acessibilidade topológica de cada eixo com relação aos demais. Quanto mais acessível ou integrado ele for, menos inflexões de percurso entre ele e outros eixos do sistema. Os aplicativos utilizados têm saída gráfica e numérica. $\mathrm{Na}$ apresentacão gráfica dos mapas produzidos, as cores quentes representam eixos mais integrados, enquanto as cores frias revelam eixos segregados. A seguinte escala de cores é adotada: vermelho é a de maior integração, seguida de laranja, amarelo, verde, azul claro e azul escuro, que representa a de menor integração (HOLANDA, 2007).

Por meio do aplicativo Mindwalk
xSpace $36^{1}$, foram gerados dois mapas para avaliar a malha viária e visualizar o panorama de integração de suas ruas da 806 Sul.

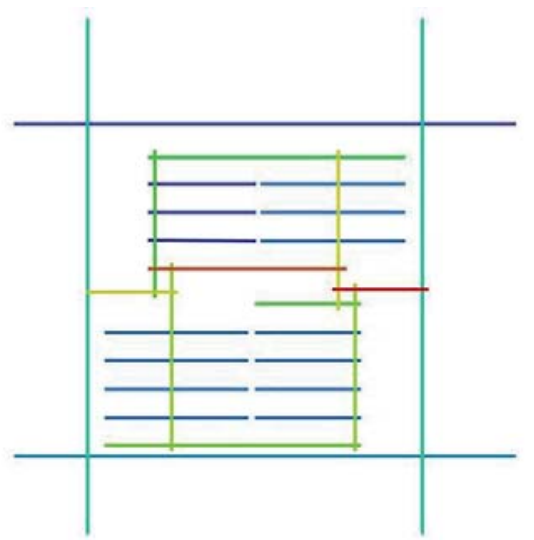

Figura 2 - Mapa axial da quadra segundo o projeto original.

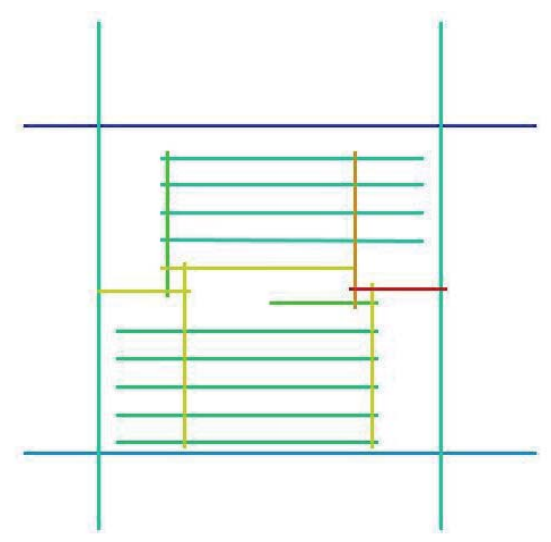

Figura 3 - Mapa axial da quadra modificada pelo uso dos moradores

No mapa gerado sob os aspectos de configuração local, que considera a quadra em si (sem levar em conta o sistema da cidade como um todo), as vias são, em sua maioria, segregadas em relação umas às outras. $\mathrm{O}$ sistema é caracterizado por ruas sem saída para veículos.

Circulando nessas mesmas ruas, percebe-se que os veículos re-criaram a integração, quando passaram a não respeitar, em todos os casos, as áreas - desertas e abandonadas - entre os culs-de-sac das vias. Assim, as ruas (antes sem saída

\footnotetext{
${ }^{1}$ Aplicativo desenvolvido por Lucas Figueiredo de Medeiros e licenciado por tempo indeterminado a Frederico de Holanda, para uso acadêmico e científico.
} 
segundo o projeto original) são unificadas como evidência do comportamento das pessoas frente à determinada configuração espacial. O exemplo, quando o espaço não atende às necessidades do usuário, ou este restringe suas ações (modificando hábitos), ou ele modifica a arquitetura conforme achar conveniente.

Com a alteração de usos das alamedas internas, o grau de integração da malha também se altera. As vias, em projeto, eram acessíveis somente pela entrada da quadra disposta nas suas proximidades. Os mapas de axiais da área mostram que as vias mais integradas são as de cores quentes, vermelho e laranja, justamente - e talvez não por coincidência - as mais próximas e, ao mesmo tempo, as que chegam aos espaços destinados aos moradores: as praças e os demais equipamentos como igreja, escola e comércio local. Justamente nesses pontos, foram feitos os levantamentos de apropriação do espaço, durante o período da tarde e no início da noite.

\section{4 À TERCEIRA VISTA: ESPAÇOS COLETIVOS E COMUNIDADE}

Ao deslocar-se pelas avenidas que contornam a quadra (NS 04 e NS 10, LO 19 e LO 21), percebe-se que, embora não haja barreiras visuais, não existem elementos de identidade visual que facilitem a orientação. Contudo são detectados sistemas de barreiras físicas à permeabilidade. Para o veículo: dois acessos únicos, localizados simetricamente em um eixo norte-sul. Situação que, para uma quadra com aproximadamente $490.000 \mathrm{~m}^{2}$, dificulta significativamente a circulação. Para o pedestre: se o transeunte não adotar os mesmos acessos veiculares (ainda que sem calçadas), terá como opção caminhar por entre becos e lotes vagos entre as edificações.

O primeiro mapeamento de uso foi feito entre as catorze e dezesseis horas de um dia de semana tradicional, do mês de abril de 2008. Para essa análise, não foram consideradas pessoas ou grupos de pessoas em veículos automotores ou bicicletas. Nos mapas, as crianças foram apontadas na cor verde as mulheres na cor rosa e os homens em preto. Os pontos com circunferência externa indicam uma pessoa 'em circulação' quando somente de passagem. Os demais pontos denotam crianças, mulheres ou homens 'em atividade', ou seja, usufruindo do equipamento urbano.

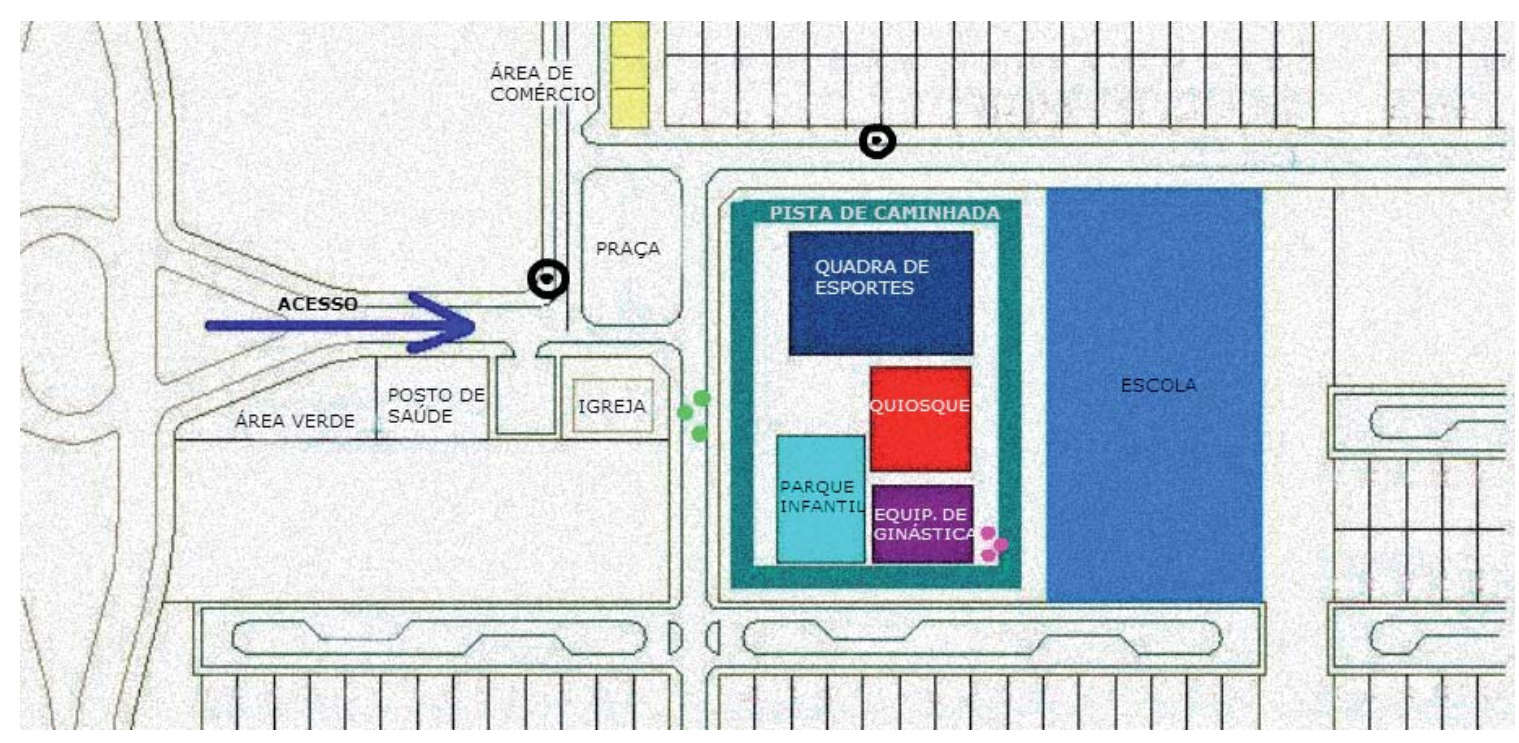

Figura 4 - Mapeamento de uso diurno do acesso oeste 


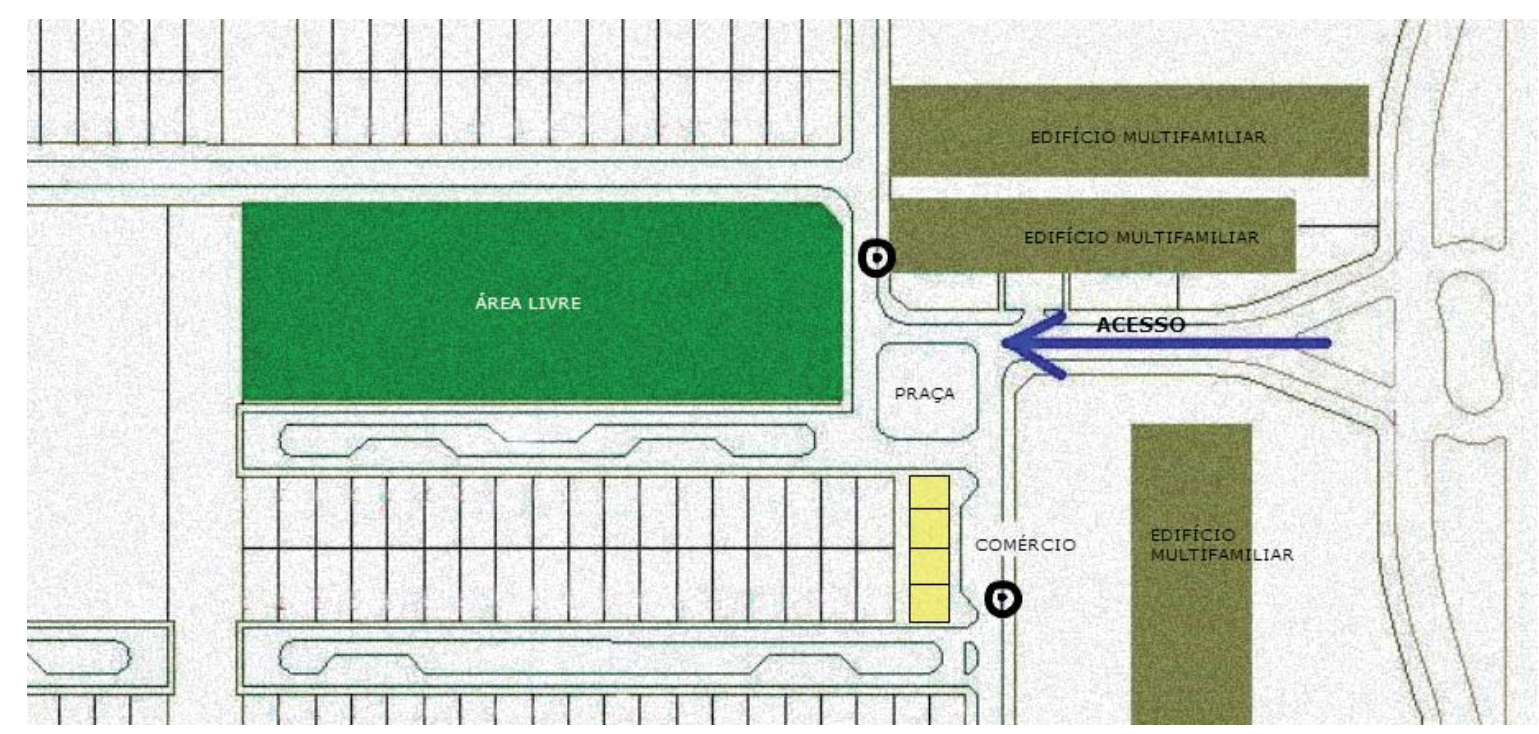

Figura 5 - Mapeamento de uso diurno do acesso leste

O mapa mostra a utilização da área destinada ao público (moradores da quadra ou de quadras vizinhas). Nesse horário, sol a pino, a praça e as ruas encontram-se praticamente vazias. Embora estejam presentes princípios de urbanidade (portas das casas voltadas para esses espaços, por exemplo), as únicas pessoas que fazem utilização dos espaços escondem-se e aglomeram-se embaixo das árvores, nas sombras. As crianças pontuadas jogam bola no meio da rua. Mesmo se arriscando ao trânsito de veículos (pouco intenso), elas optam por brincarem protegidas pelos raios solares. Do outro lado da praça, três mulheres levam cadeiras de suas casas e socializam, em grupo, sob a densa massa foliar da copa de uma árvore.

As pessoas não se aventuram a sair de suas casas sem necessidade. A praça, mesmo com atrativos (parque infantil e a quadra), não é suficientemente arborizada para abrigar mais pessoas, mesmo que elas queiram. As altas temperaturas da cidade de Palmas não podem, em hipótese alguma, ser desconsideradas. Os arbustos existentes são ainda muito novos e, além disso, plantados fora dos locais passíveis da apropriação pelas pessoas.

No sentido oposto da quadra, no segundo acesso observado, a apropriação de espaços ainda é reduzido. Durante o dia, notam-se áreas abertas desertificadas de proporções consideráveis. Aqui, a configuração urbanística favorece a acumulação de resíduos e o desenvolvimento de ervas daninhas. As únicas pessoas identificadas estavam de passagem.

Durante a noite, a concepção espacial torna-se viva e coloca os espaços em uma condição de apropriação divergente à constatada anteriormente. 


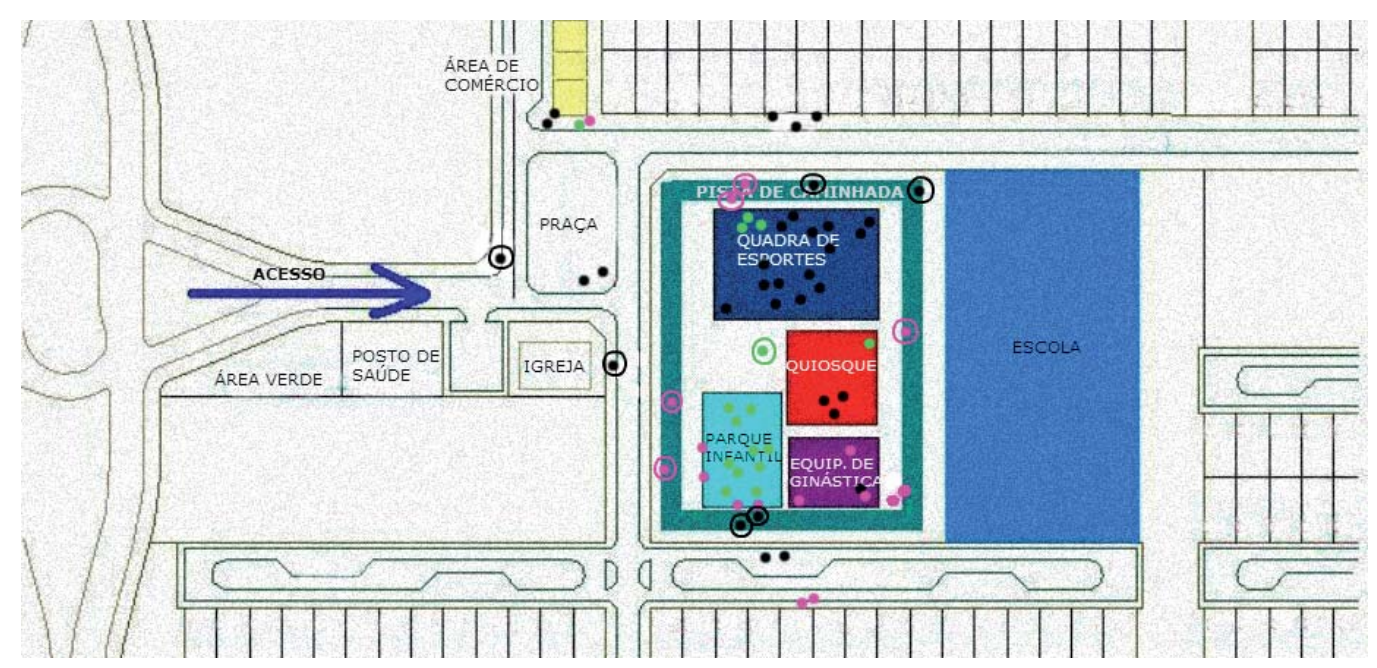

Figura 6 - Mapeamento de uso noturno do acesso oeste

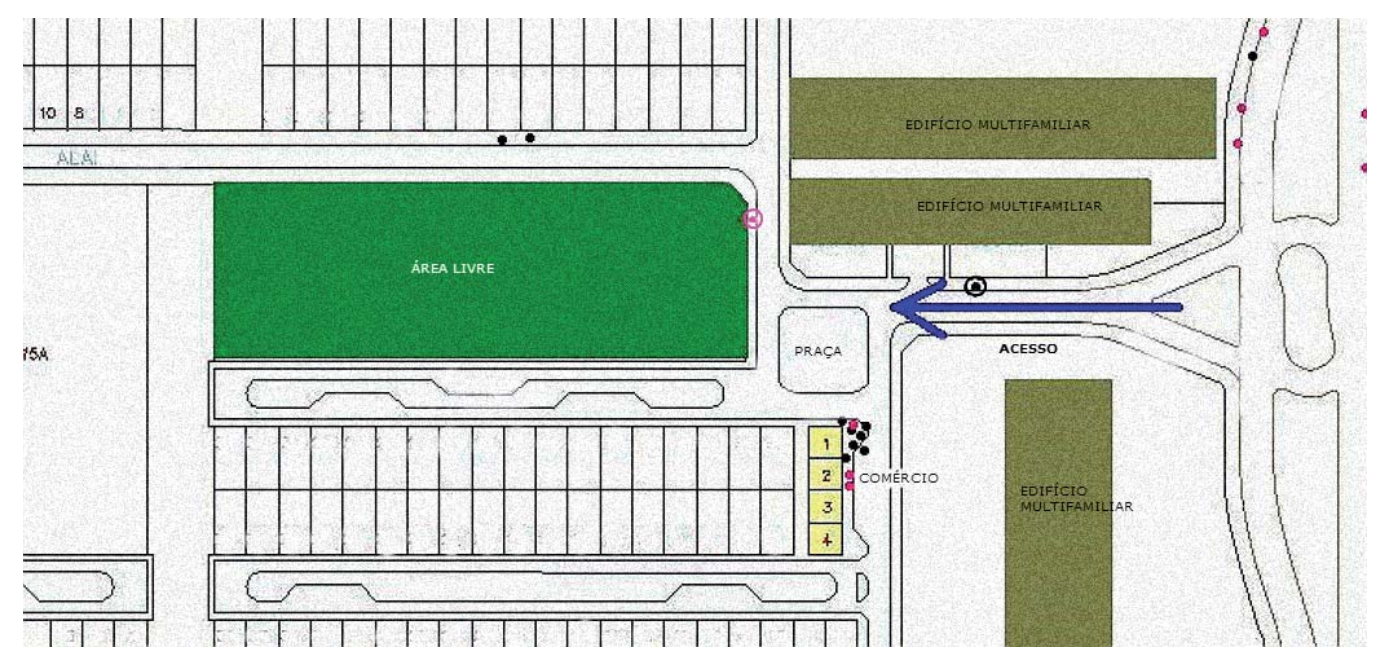

Figura 7 - Mapeamento de uso noturno do acesso leste

Na praça implantada a oeste, em um clima menos agressivo sem a ação solar, vários grupos, exercendo diversas atividades, revitalizam o espaço público: pessoas caminham ou levam os cachorros para passear, jovens jogam na quadra ou namoram no quiosque (que funciona somente no período noturno). Inúmeras crianças brincam no parquinho. A praça é bem iluminada e, nesse momento, possui equipamentos urbanos adequados e usufruídos pela comunidade.

A disposição das casas, com suas portas voltando-se para as alamedas que limitam a praça, os moradores do entorno fazem das ruas e das calçadas continuidade de suas casas, muitas vezes porque, em função do calor, a área externa às residências é mais agradável.

Do outro lado, constrói-se um quadro oposto. Os edifícios multifamiliares formam uma barreira de permeabilidade física e visual e limitam os grandes espaços livres, abertos e cegos. O acesso é pouco iluminado, e há uma concentração de pessoas na calçada frente a um bar. A barreira formada pelos edifícios da quadra para a avenida esconde ou limita uma zona de baixo meretrício, pontuado na via, imediatamente após as fronteiras que limitam a quadra. Nessa área adjacente, começa a ser aplicado um código que altera a estrutura do espaço e sua consequente utilização. Como a obrigatoriedade de 
recuos de ajardinamento (que se tornaram áreas abandonadas) e a previsão de grandes áreas livres e abertas, a tipologia edilícia moderna é potencializada. Assim, nessas áreas, a busca de um espaço "mais aberto", moderno, de densidades baixas procedentes da cidade-jardim, tem como consequência uma perda de parte da identidade do espaço público a partir da perda da sua identidade.

A configuração espacial - paredes cegas, grandes espaços abertos, iluminação deficiente - permite tal sintaxe espacial e induz a determinado comportamento humano.

\section{CONSIDERAÇÕES FINAIS}

A identificação de pontos contraditórios da quadra demonstra que a sintaxe espacial e suas estreitas relações com a arquitetura podem ser temporais e, ainda, determinadas por aspectos únicos, como a questão térmica, em que o bioclimatismo aparece como ator fundamental na extrusão da urbanidade. No caso da 806 Sul, embora estejam presentes inúmeros elementos de urbanidade, os espaços coletivos são usufruídos e apropriados à sua morfologia, mas sua utilização está condicionada ao horário, clima e temperatura. Qualquer espaço aberto na cidade de Palmas, para que seja devidamente utilizado durante o dia, deve disponibilizar de mínimo conforto térmico, ou, no caso específico, de sombra.

Durante a noite, sem o sol, os usos se intensificam, em cada ponto conforme sua configuração, contextualizado pelos diversos usos - de brincadeira de criança à prostituição - e grau de relação entre pessoas e espaços, arquitetura e sociedade.

Os resultados obtidos mostram que os objetos de estudos são contraditórios e complementares, mostrando vários aspectos da utilização de áreas públicas. Em função de configurações espaciais opostas, durante a noite temos condições desejáveis à permanência e/ou movimento de pedestres e veículos nos dois pontos. Contudo, atendendo grupos sociais de interesses divergentes: sociedade aberta, dentro dos padrões civis e familiares, de um lado e comércio da noite, prostituição (o que não se deve ver) do lado oposto.

Quando aprimoramos a sistematização de dados que fortaleçam a arquitetura como agente interventor sociológico, admitimos a necessidade de enxergar o ambiente (construído ou não) dentro de seus significados - de apropriação, simbologia, fluxos e usos das edificações - e de nos atrever a aventuras de descoberta de 'condições desejáveis' para determinadas pessoas e grupos, que se apropriam (voluntariamente ou não) de determinado espaço conforme cultura, necessidade e condições favoráveis.

O diagnóstico para intervenções futuras deve basear-se em princípios que organizem essa parcela do sistema urbano, de forma a minimizar a entropia de significados gerada pelo entorno e reduzir os impactos sociais locais e regionais. As alternativas para o planejamento devem caminhar na busca da urbanidade segundo uma lógica de sociabilidade e características locais alinhadas a uma comunidade viva, em movimento e, é claro, em constante transformação.

\section{REFERÊNCIAS}

DEL RIO, Vicente; GALLO, Haroldo. Olegado do urbanismo moderno no Brasil. Paradigma realizado ou projeto inacabado? Arquitextos, São Paulo, ano 01, nov. 2000. Disponível em: <http://www.vitruvius.com.br/revistas/ $\mathrm{read} /$ arquitextos/01.006/958>.

HOLANDA, Frederico (Org.). Arquitetura $\mathcal{E}$ urbanidade. São Paulo: ProEditores Associados, 2003.

HOLANDA, Frederico. Arquitetura sociológica. Revista Brasileira de Estudos Urbanos e Regionais, Recife, v. 9, n. 1, p. 115-129, maio 2007. Disponível em: <http:// repositorio. unb.br/bitstream/10482/12149/1/ARTIGO_ ArquiteturaSociologica.pdf $>$. 
LAMAS, José P. G. Morfologia urbana e desenho da cidade. Lisboa: Fundação Calouste Gulbentrian, Junta de Investigação Científica e Tecnológica, 1992.

PALMAS, Município [de]. Lei n. 386, de 17 de fevereiro de1993. Dispõe sobrea divisão da Área Urbana da Sede do Município em Palmas em Zonas de Uso e dá outras providências. Palmas, 1993. Disponível em: <http://www.palmas. to.gov.br/media/doc/arquivoservico/ LEI_ORDINARIA_N\%C2\%BA_386-93_ atualizada_2.pdf $>$.

Lei $n$. 468, de 6 de janeiro de 1994. Aprova o Plano Diretor Urbanístico de Palmas (PDUP) e dispõe sobre a divisão do solo do Município, para fins urbanos. Palmas, 1994. Disponível em: <http://www.cauto. gov.br/wp-content/uploads / 2013/07/ Plano-Diretor-Palmas.pdf $>$.
PESCARINI, Ismael Andrade. Revitalização de avenidas em São Paulo: considerações morfológicas. Exacta, São Paulo, n. 1, abr. 2003. p. 35-42. Disponível em: <http:// www.vitruvius.com.br/revistas/read/ minhacidade/03.033/2044>.

SILVA, Luiz Otávio Rodrigues. A formação de Palmas. 2002. Dissertação (Mestrado em Arquitetura e Urbanismo) - Universidade de Brasília, Brasília, DF, 2002.

SILVA, Valéria Cristina Pereira da. Palmas, a última capital projetada do século XX: uma cidade em busca do tempo. São Paulo: UNESP, 2010. Disponível em: <http:/ / static.scielo.org/scielobooks/c3qn3/pdf/ silva-9788579830921.pdf>.

SOUZA, Candice Vidal e. A cidade imaginada: a construção de Palmas nos discursos políticos e urbanistas. Brasília: UnB, 1992.

\section{Sobre a autora:}

Nicole de Castro Pereira: Doutoranda pela Curtin University, Austrália. Mestre pela UnB e Docente no Instituto Federal de São Paulo. Bolsista do CNPq pelo Programa Ciências Sem Fronteiras. E-mail: nicole@ifsp.edu.br 